\title{
Intencionalidad y ausencia en El ser y la nada de Jean-Paul Sartre*
}

\author{
Wilfer Alexis Yepes Muñoz**
}

Recibido: 18 de enero de 2016

Evaluado: 10 de marzo de 2016

Aceptado: 1 de abril de 2016

\section{Resumen}

Esta reflexión rehúnde sus raíces en la tensión original de la conciencia con su correlato, esto es, de la conciencia como conciencia de algo. Sobre este pilar de la fenomenología husserliana, Sartre construye las estructuras del para-sí que, en la segunda y en la tercera parte de El ser y la nada, enmarcan esa tensión entre la nada humana como para-sí y el en-sí como ser macizo. Esa conciencia, por tanto, pasará a ser una conciencia de nada como conciencia refleja, permitiendo que se instaure en esa relación ontológica con el ser una ausencia en la comprensión total de la condición humana. En esta perspectiva se construirá una ontología del obrar humano como construcción de un ser personal siempre aplazado, es decir, ausente. Esta reflexión pretende, por tanto, una lectura del texto que vincule la intencionalidad como pilar de la fenomenología con el concepto de ausencia como componente subyacente a la tensión en-sí-para-sí. El texto se divide en tres momentos: la nada, la ausencia y el ser; la ausencia como negatividad creadora; y el obrar ontológico.

Palabras clave: Intencionalidad, ausencia, libertad, existencia, Sartre.

* Este artículo es producto de la investigación de Maestría en Filosofía, presentada en la Universidad Pontificia Bolivariana, sede Medellín en el año 2012. DOI: http://dx.doi. org/10.15332/s1794-3841.2017.0027.04

** Doctor y Magíster en Filosofía, Filósofo y Licenciado en Filosofía y Letras por la Universidad Pontificia Bolivariana, sede Medellín. Se ha desempeñado como docente de cátedra en la Facultad de Filosofía de la universidad en mención. Su investigación se centra en la filosofía francesa del siglo XX, hermenéutica, estética y la relación filosofía-literatura. ID ORCID: 0000-0001-5782-2732 E-mail: waymes4@hotmail.com 


\section{Intentionality and Absence in Being and nothingness by Jean Paul Sartre}

\begin{abstract}
This reflection is at the original tension of consciousness with its counterpart, that is, of consciousness as consciousness of something. On this pillar of Husserl's phenomenology, Sartre builds the structures for itself, in the second and third part of Being and Nothingness will frame the tension between human and nothing for itself and the in-itself as massif being. That awareness therefore becomes a consciousness of anything as reflected consciousness, allowing it to put in place in the ontological relation to being an absence in the full understanding of the human condition. In this perspective an ontology of human action as building personal always be postponed, that is, absent will be built. This reflection intended, therefore, a reading of the text linking intentionality as a pillar of phenomenology with the concept of absence as underlying tension between in-itself-itself. The text is divided into three stages: nothingness, absence and being; absence as creative negativity; the ontological act.
\end{abstract}

Key words: Intentionality, absence, freedom, existence, Sartre.
Received: January 18, 2016

Evaluated: March 10, 2016

Accepted: April 1, 2016 


\section{Intencionalidade e ausência em 0 ser e o nada de Jean-Paul Sartre}

Received: January 18, 2016

Evaluated: March 10, 2016

Accepted: April 1, 2016

\section{RESUMO}

Esta reflexão afunda suas raízes na tensão original da consciência com seu correlato, isto é, da consciência como consciência de algo. Sobre este pilar da fenomenologia husserliana, Sartre constrói as estruturas do para-si que na segunda e na terceira parte de O ser e o nada, delimitam essa tensão entre a nada humana como para-si e o em-si como ser maciço. Esta consciência, por tanto, passará a ser uma consciência de nada como consciência reflete, permitindo que se instaure em essa relação ontológica com o ser uma ausência na compressão total da condição humana. Nesta perspectiva se construirá uma ontologia do obrar humano como construção de um ser pessoal sempre adiado, aliás, ausente. Esta reflexão pretende, por tanto, uma leitura do texto que vincule a intencionalidade como pilar da fenomenologia com o conceito de ausência como componente subjacente à tensão em-si-para-si. O texto se divide em três momentos: a nada, a ausência e o ser; a ausência como negatividade criadora; e o obrar ontológico.

Palavras-chave: Intencionalidade, ausência, liberdade, existência, Sartre. 


\section{INTRODUCCIÓN}

Esta reflexión parte de un concepto que Sartre utiliza a menudo en El ser y la nada cuando comienza a delimitar los bordes de la tensión en-sí-para-sí: la ausencia. Los mencionados conceptos en tensión se remontan a la filosofía de Hegel, pero adoptan un cariz fenomenológico que no podrá abandonar la intencionalidad de la filosofía husserliana. Se pretende, por tanto, dilucidar una confrontación del concepto de intencionalidad con la ausencia, porque en este punto emergerá la negación. El problema de la Nada, que constituye la primera parte de esta obra de 1943, parte de la concepción de fenómeno e intencionalidad husserlianos, encaminándose al problema de la nada como punto de «distinción» del para-sí: la conciencia de algo en Sartre hace emerger la nada del otro lado del mundo. En otras palabras, el para-sí tematiza el en-sí en tanto ausencia de ser. En los demás capítulos de la segunda ( $E l$ ser para-si), tercera (El para-otro) y cuarta parte (Tener, hacer y ser) del texto se ensamblarán las estructuras y relaciones a partir de esta nada que se origina como conciencia de ser y conciencia de nada.

Iniciemos este camino con un presupuesto: el hombre es lo que hay del otro lado del mundo. Con esta analogía destacamos la nada, la indefinimos, la ubicamos del lado de la conciencia de nada, como resultado de esa diferencia primera: hombre-mundo. Por ello, la intencionalidad que configura su ser-enel-mundo no basta, no basta el conocimiento, no bastan las problematizaciones y los recuerdos de aquello que ha consolidado una cierta imagen de sí mismo. En todo hombre, la necesidad impulsa, desborda, se rebela y se contrapone a un ser ya dado o ya sido.
No es suficiente una categoría que abarque nuestro antes y nuestro después, porque al incluir la temporalidad en esta dinámica del no ser lo que se es, la libertad y la exigencia de ser ejercen sobre nuestra nada un llamamiento ineludible. La esencia no sería más que una búsqueda de sentido, una interminable búsqueda, recordando la premisa célebre del existencialismo sartriano: «La existencia precede la esencia» (Sartre, 2008, p. 636). Esa filosofía ve en el hombre esa búsqueda, esa intencionalidad. Pero esa intencionalidad, ¿lo es de verdades o de sentido? ¿De esencia o de ausencia? Buscamos en el mundo algo, sentimos que hemos perdido algo, percibimos en nuestras vidas un vacío de algo. Con una diferencia clara: ese algo profundo nos revela la nada, no solo como un vacío de algo, sino también como una necesidad imperiosa de vaciamiento. Sartre dilucida esa intencionalidad en el siguiente fragmento de El ser y la nada:

Toda conciencia está falta de... para. Pero ha de comprenderse bien que la falta no le viene de afuera, como la del fragmento de luna a la luna. La falta del para-sí es una falta que es él. Lo que constituye el ser del para-sí como fundamento de su propia nada es el esbozo de una presencia a sí como lo que falta al para-sí. El posible es una ausencia constitutiva de la conciencia en tanto que esta se hace a sí misma. (Sartre, p. 163)

Tomar conciencia, en nuestra lectura, exige un vaciamiento de sí, una negación del en-sí que intencionamos; aunque también es un perderse, un derrocharse mundo. La nada aparece como un elemento en algún modo trágico. Incluso si nos aventuramos a interpretar El ser y la nada desde un enfoque 
meramente gnoseológico, encontramos en esta obra una visión trágica del conocimiento: un hombre sin esencia es un hombre que tiene que configurar el mundo a partir de esa necesidad, es decir, un hombre no solo condenado a ser libre, sino también condenado a intencionar, a distanciarse de sí, a crearse en el conocimiento de su ser-en-el mundo como un en-otra-parte, como diferenciación permanente del en-sí:

El para-sí surge como nihilización del en-sí, y esta nihilización se define como proyecto hacia el en-sí: entre el en-sí nihilizado y el en-sí proyectado, el para-sí es nada. Así, el objetivo y el fin de la nihilización que soy es el en-sí. Luego, la realidad humana es deseo de ser-ensí. Pero el en-sí que ella desea no puede ser puro en-sí contingente y absurdo, comparable de todo punto al que ella encuentra y nihiliza. La nihilización, como hemos visto, es asimilable, en efecto, a una rebelión del en-sí que se nihiliza contra su contingencia. (Sartre, 2008, p. 763)

La relación entre el en-sí y el para-sí no se reduce a una mera búsqueda de seguridades o al intento de posesión del mundo como verdad. El para-sí se distingue del en-sí porque constituye su propia nihilización como ensí. En este sentido, podemos traer esa intencionalidad que se nihiliza como diferencia a un concepto que en adelante llamaremos intención profunda, porque es justamente en la intencionalidad de la conciencia de algo donde viabilizamos la necesidad de justificar el ser, lograr la síntesis en-sí-para-sí. La intencionalidad profunda reside en la nada, en la necesidad de negarse como en-sí, de buscar un sentido en el obrar, en las relaciones con el otro, en la soledad de una autocreación acuciante, porque la nada es solo eso: la necesidad de auto-creación, la exigencia, la responsabilidad. Esta necesidad enlazada a dos condiciones fundamentales. Primero, que podemos llamar intención de cosas, la negación previa en tanto negación de diferenciación: la conciencia como conciencia de algo. Y, en segundo lugar, la de ser para otros como un encadenamiento de intereses reunidos en una misma intención profunda: la conciencia como conciencia de nada, el hombre que hay del otro lado del mundo. Por ello, es claro que el conocimiento no puede conducirnos a la concordancia con el mundo. Rüdiger Safranski plantea esa esperanza sobre la que se funda el conocimiento del mundo:

La razón estriba en la esperanza obvia de que, a la postre, el conocimiento conduce siempre a los fundamentos válidos que sostienen al hombre y le otorgan el sentimiento de estar en casa. El conocimiento fue concebido como una medida capaz de crear confianza. Conduce a la concordancia con el mundo. (Safranski, 2005, p. 218)

En esa necesidad de conocimiento, el pensamiento occidental ha olvidado lo más humano del hombre, ha conducido a la concordancia con el mundo sin la diferenciación de la conciencia de nada. Una esencia impuesta es un don, pero también una condena. Por su parte, Sartre aliviana esa condena con un núcleo dinámico; un punto de referencia que nos ex-pone y responsabiliza: «estoy condenado a existir para siempre allende mi esencia, allende los móviles y motivos de mi acto: estoy condenado a ser libre. Esto significa que no podrían encontrarse a mi libertad otros límites que ella misma, o, si se prefiere, que no somos 
libres de cesar de ser libres» (Sartre, 2008, p. 599). Tenemos que cargar con el peso de un suelo ontológico. La libertad sería ese punto de partida en tanto nada que se nihiliza a sí misma como ser pleno. En efecto, encontramos que, en la apuesta de Sartre, esa libertad es un suelo que se agita y admite -incluso exige- el obrar como parte esencial del arrojamiento.

No llegamos a la esencia como al atardecer de la vida. No arrancamos de las acciones un sentido, una huella y una influencia compleja de un en-sí que nos recordó siempre la nada, la intencionalidad profundamente humana que subyace a todo programa epistémico. No miramos con los ojos de la esencia, de un ser propio que es prestado. Miramos el mundo como quien avizora su propia imagen. Pero el existencialismo nos entrega una ruptura frente a la teoría del conocimiento: conocer, tender por naturaleza a conocer envuelve una intencionalidad existencial: ese hombre arrojado es la nada, su propia nada. Ahora bien, esta nada no es alguien estable. Esta nada se impulsa a ser, aunque tiene que nadificarse. Tiene que hacerse nada. $\mathrm{Y}$ a pesar de llenarse, de historizarse, es un vaciamiento, un conocimiento de nada, un reconocimiento de su ausencia. El hombre es la ausencia, la falta de ese ser que posibilita su obrar.

Reactivemos la idea de un hombre complejo, problemático e indeterminado que interpretaremos en un trasfondo de intereses ontológico-antropológicos. Un hombre siempre remitido, tematizante del en-sí, de intencionalidades que configuran el conocimiento más como una búsqueda de sentido que como una odisea de la verdad. En efecto, este hombre inesencial nos remite al vacío, al esfuerzo cotidiano que da fe de su búsqueda del principio partiendo de un núcleo que no puede cerrarse, porque siempre está escindido. En la libertad, siendo núcleo o fundamento del ser del hombre, toda acción es susceptible de reactivación, toda acción es un poner en el en-sí la necesidad de hacerse con la necesidad de crearse sin fin. Ese creador que es la misma nada, en su creación -creación de nada y de ser-, descubre la responsabilidad insalvable de hacerse.

¿Llegaremos a pensar la esencia como quietud equiparada a la muerte? ¿Será suficiente comprender la condición humana en El sery la nada a partir de la ausencia? Si es suficiente la ausencia, ¿qué obstáculos hallaremos a nuestro paso? ¿Tendremos que aceptar la nada como núcleo que vence la idea de un ser pleno que no nos corresponde? Avancemos en la respuesta a estos interrogantes dividiendo la reflexión en tres momentos, recurriendo a algunos estudios de la obra de Sartre y centrándonos principalmente en los planteamientos de su obra de 1943: el primer momento, lo llamaremos la nada, la ausencia y el ser: el segundo, por la cercanía de la ausencia con el obrar, la ausencia como negatividad creadora y, finalmente, el obrar ontológico.

\section{LA NADA, LA AUSENCIA Y EL SER}

Al hablar de la conciencia tenemos que remitirnos a la nada. La conciencia por sí sola no es posible, ni siquiera pensable; es siempre una nada referida, una nada que tiene que nihilizarse como nada y como ser. De este modo, cuando aludimos a la conciencia, tenemos que incluir su correlato: «toda conciencia, como lo ha mostrado Husserl, es conciencia de algo. Esto significa que no hay 
conciencia que no sea posición de un objeto trascendente, o, si se prefiere, que la conciencia no tiene «contenido» (Sartre, 2008, p. 18). Por este motivo, nuestra visión del mundo como incorporación de la conciencia, incluso como su ser, un ser intencionado, descentrado, envuelve no solo el en-sí, sino también una nada que más allá de un programa cognoscitivo se arraiga en una intención profunda: el ser, la ausencia (Sartre, 2008 , p. 211). Claro está, aunque la atraviesa una ausencia de orden ontológico, preferimos el nombre ausencia, ya que en este concepto inscribiremos la tensión subyacente a ese ser y a esa nada.

En este trayecto subordinaremos el conocimiento y la configuración del en-sí a una intención profunda que construye y afirma el ser del en-sí como plenitud, pero al mismo tiempo como el reflejo de una problematización que aparece justo en el momento en que la conciencia nihiliza el en-sí, buscando e incluso pre-ocupando su ser. En esa intención profunda existe un llamado del ser, sumado a un llamado a ser. Cuando somos conscientes de este llamado en una relación, en una intención de cosas, descubrimos también que Sartre emprendió la construcción de sus categorías en un plano humano del conocimiento, enmarcando así su postura de existencialista, es decir, pasando de la conciencia como conciencia de algo a esa nada que se constituye a sí misma en el obrar.

En ese juego serio de la existencia, la nada que nos revelamos y el ser que nos urge, incluso el ser que nos instiga aparece como posibilidad, es decir, como mi ser, un devenir aplazado, nunca logrado, y mi nada, que reconoce, se llena, actúa, elige, aunque siempre tiene que vaciarse. Su necesidad no es suprimida. Nuestra hipótesis es que a esa nada y a ese ser subyace la ausencia. Para nosotros, la existencia consiste en esa $a u$ sencia, en esa oscilación de conocimiento y de re-conocimiento a pesar de no encontrar una habitación segura a su paso que le permita reconocerse plena en el conocimiento y en la construcción de posibilidades; esa tensión queda reducida a proyecto. El ser y la nada, mi nada y mi ser quedan en tensión.

Teniendo en cuenta las reflexiones preliminares en torno a la ausencia, tenemos que preguntar: ¿por qué la condición humana del para-sí puede concebirse en términos de ausencia? ¿Cómo entiende Sartre esta ausencia? ¿Qué elementos de esta propuesta se acercan a la relación primordial nada-ser? Comenzar a plantear una reflexión sobre la ausencia desde El ser y la nada implica entrar a las condiciones de posibilidad de esa relación en-sí-para-sí, a las intenciones profundas que encontramos al hablar de un conocimiento más humano para superar el idealismo que criticó Sartre de sus maestros más cercanos, especialmente Husserl, incluso de una tradición filosófica que justificó el hombre a partir de una determinación esencial. Para ilustrar esta afirmación, transcribamos la crítica que plantea Sartre contra Leibniz:

Pero hay aquí un error análogo al que señalábamos antes en Leibniz, aunque situado en el otro extremo de la existencia. Para Leibniz, somos libres, puesto que todos nuestros actos emanan de nuestra esencia. Pero basta que nuestra esencia no haya sido elegida por nosotros para que toda esa libertad de detalle recubra una total servidumbre: Dios ha elegido la esencia de Adán. (Sartre, 2008, p. 728) 
La tensión del hombre contemporáneo consiste en el desplazamiento del ser a la nada; esto indica que es también la lucha existencial de un hombre nostálgico, un hombre que elige e intenta superar esa indigencia originaria, legada por Sartre. Por ello al iniciar esta reflexión ubicamos al hombre de ese otro lado del mundo. No obstante, tenemos que ubicarlo en una tensión: del otro lado del mundo, pero buscando entrar, hacer parte de ese mundo, por lo menos en lo correspondiente a algo: la plenitud.

Cuando encontramos el hombre del lado de la nada, la nada que posibilita, pero la nada que nihiliza y se intenciona, hallamos en el fondo una problematización. Sartre reconoce que del lado del hombre no hay más que deseo y conciencia de deseo (Sartre, 2008, p. 146). En nuestra interpretación, el deseo es inherente a la conciencia de nada, ya que la nada desea ser, haciendo emerger la ausencia, la conciencia de nada.

Elección, acción, libertad y angustia tienen que remitirnos a esa conciencia de nada como intención profunda de todo programa cognoscitivo. Estar frente al mundo es estar frente a esa posibilidad de ser, frente a esa plenitud con la que podríamos identificarnos si no respondiéramos al llamado. Pero el ser también es vocación, llamado a ser. Para ser llamados, tenemos que asumir nuestra conciencia de nada. Sin la conciencia de nada, que recorre El ser y la nada, no sería posible la tensión de la que hablamos.

López al comparar a Sartre con la propuesta de Merleau-Ponty, insinúa una reducción que viabiliza esa tensión: «Sartre antropologiza la nada heideggeriana, mientras que Merleau-Ponty antropologiza y mundaniza el ser. A diferencia de Heidegger, la nada de Sartre no es un simple correlato de la trascendencia, sino que es su estructura original» (López, 2003, p. 85). Esta antropologización se hace explícita en el proceso de nihilización realizado por el para-sí. El hombre se hace nada para-sí mismo, situando el ser en el plano de la negación: su nada es un llamado a ser. En efecto, la nada se humaniza en este llamado ontológico a ser.

La intuición fenomenológica es también reconocimiento de una falta esencial: hemos sido arrojados como conciencia de algo, pero nos regresamos a una conciencia problemática: el para-sí tiene que nihilizarse, obrarse, vaciarse, negarse y alejarse. Por ello, la libertad sartriana tiene que desprenderse de una carencia y no de una plenitud, es conciencia sin máscara, conciencia de nada, conciencia de mi nada.

La ausencia atraviesa la relación ser-nada. La ausencia que surge de las relaciones ser-nada y en-sí-para-sí movilizan la posibilidad de un obrar sin la plenitud del ser, sin la esencia que lo haga ser lo que es, un ser. Podemos aventurarnos a pensar que la esencia no es ni siquiera posterior a la existencia. La esencia siempre ha estado ahí. Solo que no podemos tomarla y reducirla a un en-sí; no puede existir una identificación total con el en-sí. Nuestra esencia se nihiliza en la medida en que somos conciencia de algo, existentes del otro lado del mundo.

Sartre lleva nuestra interpretación a este punto, ya que cuando estudiamos la existencia, hablar de la existencia implica hablar de la esencia. Pero además hay que distanciar la existencia de la esencia para que la nada se humanice. De lo contrario, identificar la nada con la esencia sería caer en un error: la nada como Nada no existe, es impensable. 
Sartre se desliga de la Nada parmenídea. Por ello, estamos de acuerdo con Paul Roubiczek (1968) cuando afirma que «Sartre trata de escapar de esta nada sin límites; quiere salvar la dignidad del hombre y asegurar su responsabilidad» (Roubiczek, 1968, p. 121).

La nada tiene que nihilizar el correlato y nihilizarse a sí misma, posibilitando un ser inacabado, un ser que se tiene que vaciar de sí mismo. Es que ser para-sí comprende un ser conciencia de nada, ser para-sí implica distancia de sí, distancia de mundo, vaciamiento propio, intuición eidética $\mathrm{y}$, así mismo, vínculo original entre ese mundo como en-sí y mi ser proyectado. El hombre es esa ausencia precisamente, porque está en medio de ese mundo y de su ser proyectado; está en medio de su nada y la posibilidad de retratar la plenitud. De esta manera, podemos considerar que si pensamos lo que somos en el modo de ser lo que somos, estamos negando la posibilidad de afirmar la nada como un componente ontológico posibilitante, que nos entrega lo que somos en el modo de la no-conformidad. Afirmar lo que no somos sería simular y, por tanto, romper esa tensión. La existencia es siempre tensión: «El existente no posee su esencia como una cualidad presente. Hasta es negación de la esencia: el verde no es jamás verde. La esencia viene al existente desde el fondo del porvenir, como un sentido que nunca es dado y que lo infesta siempre» (Sartre, 2008, p. 277).

Ahora bien, ¿cómo entiende Sartre esta ausencia? No como una condición previa que se cierra sobre sí misma, sino como una condición primera de acceso al mundo: «El hombre se anuncia a sí mismo del otro lado del mundo, y retorna a interiorizarse hacia sí mismo, a partir del horizonte: el hombre es «un ser de alejamientos»» (Sartre, 2008, p. 59). Ausencia significa ausentarse, buscar, inventarse a sí mismo, perderse, tentar el ser. Ese ser de alejamientos es la conciencia de nada, el horizonte donde fusionamos nuestro suelo y la necesidad conquistar la cima. Estamos siempre en la distancia, lejos de nosotros, de lo que somos en el modo negativo. Nuestro ser está en suspenso.

Siguiendo la reflexión anterior, la conciencia de nada representa movimiento, inclinación, fluctuación, vaivén, hacer visible la miseria, el deseo, la ausencia. La existencia constituye el actuar siempre sin eludir un reconocimiento básico: ese ser actual no coincide con nuestra conciencia. En ella pervive la necesidad; por ello tiene que alejarse, actuar en fuga, insistir, sopesar, tentar, buscar en el mundo, proyectarse para no reducirse a ensí. Su condición no le permite una reducción entitativa. Su construcción es ontológica, trata siempre de no rendirse, trata de no olvidar. Y no olvidar lo que somos es no olvidar que podemos ser en la distancia. Lo que debemos hacer entra en el plano de la tensión ser-nada, tensión que nos permite enmarcar el obrar como un obrar el ser.

\section{LA AUSENCIA COMO NEGATIVIDAD CREADORA}

Sin la nada en tanto condición del hombre y como ser-en-el-mundo, la intención profunda carece de sentido. Ahora bien, ¿cuál es esa intención profunda que subyace al binomio ser-nada? Esta intención tiene que habérselas con dos grupos de relaciones estrechamente ligadas: la intención de cosas o relación en-sí-para-sí, y la intención profunda del binomio mi ser-mi nada como un programa latente en la obra de Sartre. 
En la intención de cosas, el para-sí tematiza realizando una primera negación: se hace-en-el-mundo, respondiendo a su arrojamiento originario; existe en la medida en que hace posible ese mundo. Pero hacer posible el mundo mediante la intención de cosas no significa hacer posible mi ser: «la realidad humana, siendo acto, no puede concebirse sino como ruptura con lo dado, con su ser. Ella es el ser que hace que haya algo dado, rompiendo con ello e iluminándolo a la luz de lo aún-no-existente» (Sartre, 2008, p. 650).

Esta ontología está situada del lado del vaciamiento; la posesión de entornos, experiencias y tematizaciones no corresponde necesariamente al ser del hombre; no existe una identificación con el mundo. Tenemos que aplicar la negación a esa relación. Primera negación, la negación del vaciamiento, la que tiene que habérselas con aquella tensión que encuentra la nada, pero no la ausencia. Esta intención consiste en llenar el mundo de intenciones, hacer posible la significación del ser y no tanto la posesión. Sartre reclama también un conocimiento en el espacio de la negación:

La cosa es, antes de toda comparación, antes de toda construcción, lo que está presente a la conciencia como no siendo conciencia. La relación originaria de presencia, como fundamento del conocimiento, es negativa. Pero, como la negación viene al mundo por medio del para-sí y la cosa es lo que es, en la indiferencia absoluta de la identidad, la cosa no puede ponerse como siendo el para-sí. (Sartre, 2008, p. 252)

Conocer no es coincidir con lo conocido, conocer no es alivianar la necesidad; conocer no significa calmar la sed de ser; conocer no es tomar el ser por el cuello. Así, el ser del conocimiento no coincide con el ser del para-sí. Recurrimos a una especie de vaciamiento. Ser-en-el-mundo consiste en intencionar la conciencia, desplegarla, sacarla, desprender de la intencionalidad tematizante una negación de sí. Por tal motivo, la conciencia deviene conciencia de nada. No corresponde con el correlato; solo se hace posible en la situación de un hacerse fuera, de un jugar a ser a partir de la negación. Su actitud de apropiación recobra algo más: en la relación en-sí-para-sí, mi ser y mi nada nunca confluyen. Así la intención profunda encierra un problema. Mi ser no es el en-sí, sino la necesidad de en-sí, la necesidad de plenitud que cobija toda orientación ontológica de apropiación. Y el para-sí coincide con la relación mi-ser-mi-nada. El para-sí está en tensión; una tensión que vacía la primera tensión, que es posesión para crear una imagen de no-correspondencia con la intención originaria.

La intención profunda es tensión originaria, nos revela lo fallido, lo ausente, lo consciente, que es lo mismo que in-tensión, es decir, la tensión de la existencia desprendida de toda justificación anterior. En esta negatividad primera, que desprende la negación profunda de la negación como en-sí se refleja la necesidad de colmar lo faltante, de sustraer, de responder a una totalidad desrealizada de suyo, de trascender y no ser más que un fingimiento de ser cuando juega en correlación. A veces conocer se convierte en un poner máscaras al para-sí, confundirlo con lo conocido, identificarlo con aquella imagen, con aquel residuo de la intención de cosas.

Lo que el hombre niega no es el ser; el ser es innegable. También la nada como un 
desprenderse. Pero al entrar en una negación del ser enmarcado en la nada, la esencia queda en suspenso. La esencia es algo negativo, como una imagen que se tiene, pero una imagen teleológica. Digamos que, en la intención profunda, sí es posible delimitar el sentido de la tensión, y el sentido de la tensión revela la temporalidad como condición necesaria de suspensión, pero, al mismo tiempo, como un enfrentamiento de la libertad.

Podríamos comprender la ausencia en dos sentidos: en sentido positivo, como tematización del en-sí. Existe un interés primero de negación en la reducción en-sí-para-sí. El para-sí tiende al en-sí al mismo tiempo que se distancia del en-sí. En este punto, la reflexión de Sartre es mucho más cercana a Husserl $^{1}$ en cuanto toma de él la relación fenomenológica de la conciencia como intentio o tendencia ineludible a su correlato. Pero esa conciencia reduce el plano de la idealización, porque no podemos idealizar la esencia en consonancia con una reducción eidética como la explica Cruz:

En la reducción eidética, como lo indica su nombre, el reducendo es lo eidético y lo reducido lo psíquico como algo fáctico. Esta reducción se logra mediante lo que Husserl llama el método de las variaciones. Tomo un hecho psíquico,

1 Uribe expresa este vínculo citando a Colette Audry: «Colette Audry decía igualmente que "El ser y la nada era la obra de un joven filósofo en rebelión contra una formación idealista y racionalista, bajo la influencia de la fenomenología alemana; el libro de un solitario alimentado con libros, animado en sus investigaciones por el deseo de dar cuenta racionalmente de lo irracional y llevado así a describir una dialéctica del individuo». En esta obra, efectivamente, Sartre rechazaba el idealismo y expresaba su idea esencial, que había concebido desde sus cursos de filosofía, y por la cual fue a Alemania a estudiar a Husserl: "que toda teoría que no dijera que la conciencia ve los objetos exteriores tal como son, estaba condenada al fracasom» (Uribe, 2005, p. 74). v. gr., una percepción. Esta es algo fáctico, algo individual y temporal; es, pues, mi percepción en este momento y con una figura determinada: la percepción de este árbol. Pues bien, para llevar a cabo la reducción considero otras percepciones reales o me imagino otras posibles. En tales variaciones hago a un lado lo variante: lo específico de cada percepción individual, y retengo lo invariante: lo común a todas ellas. Lo que resulta de esta operación es la esencia de la percepción en general, o sea, su eidos. (Cruz, 2001, p. 87)

Existe una escisión con la idealización de la conciencia para justificar el fenómeno y la reducción fenomenológica. En este punto, Sartre se acerca a Heidegger. Por ello recurre a la autenticidad y a la historicidad del Dasein, y lo hace precisamente para aproximarse a la pregunta por el ser como lo explica Uribe:

Las nociones de autenticidad e historicidad, vinculadas al concepto de hombre, son las principales nociones que Sartre toma de Heidegger. Simone de Beauvoir relata en sus memorias que Sartre leía a Heidegger desde principios de 1939, en la traducción de Corbin y del texto alemán: «...Me explicaba lo que significaba la definición del hombre como 'ser de lejanías' y cómo 'el mundo se revela en el horizonte de los instrumentos descompuestos'... Sartre, a quien siempre le había importado, en primer lugar, salvar la realidad del mundo, apreciaba en la filosofía de Heidegger una manera de reconciliar lo objetivo con lo subjetivo; no la consideraba muy rigurosa, pero era rica en sugerencias». (Uribe, 2005, p. 77) 
La reducción de la nada heideggeriana a un plano antropológico aleja a Sartre de Heidegger. Además, nuestra hipótesis no es que solo reduzca la nada, sino también el ser, pero del lado de la intención profunda, o más bien se concentra en este aspecto, llevándolo hasta sus últimas consecuencias. Heidegger en Ser y tiempo despliega un análisis existencial en consonancia con su denuncia del olvido del ser, y no un existencialismo. Si en la intención profunda encontramos el ser de la posibilidad y la negación de toda reducción, esa ausencia genera una especie de demarcación existencialista más que reducción de la nada a conciencia de nada, puesto que la nada no se patentiza; la nada se nihiliza a sí misma.

Ya avizoramos la ausencia del lado de la nada humana: pasamos de la tematización a la problematización. En nuestro caso, la ontología de la ausencia equivale a un tirar las máscaras. La ausencia es conciencia sin máscara que reconoce su carencia y su deseo, motor de elección y de obra, pero también es acción creadora.

La ausencia no se reduce únicamente a tensión de vaciamiento. También lo es de creación, de auto-creación. Sin embargo, es necesario aclarar que esa autocreación no se basta con la suma de todas las acciones. Esa autocreación proyecta siempre sin olvidar la sombra de lo que proyecta: en la búsqueda de mi ser. Me encuentro siempre con un ser sin máscara, una sombra que impulsa, sitúa, responde y niega: la libertad orientada al ser, eligiéndose proyecto, posibilitando ese hombre inconcluso. Ahora bien, las relaciones humanas se hacen posibles a partir de un encadenamiento, unido a ese deseo. El ser-para-otro es tan importante como la relación en-sí-para-sí como lo explica Sartre en la tercera parte de El ser y la nada:

Y el prójimo es el mediador indispensable entre mí y mí mismo: tengo vergüenza de mí tal como me aparezca al prójimo. $\mathrm{Y}$, por la aparición misma de un prójimo, estoy en condiciones de formular un juicio sobre mí mismo como sobre un objeto, pues al prójimo me aparezco como objeto. (Sartre, 2008, p. 314)

Las relaciones con el prójimo se desprenden de una negatividad aprendida que no es posible por fuera del mundo; un mundo que es a fin de cuentas humano. Las relaciones con el otro nos permiten reconocer en el otro esa condición de igualdad, que es a su vez condición de exigencia. Mirar al otro cosificándolo debe situarnos en el plano de la construcción intersubjetiva de un hombre común que posibilita la esencia a partir de acciones participativas y no jerárquicas. El problema de Sartre fue comprender esa cosificación a partir de una conciencia vertical del otro, que no asiente el reconocimiento de la indigencia, de lo que falta. Esto explica por qué tener algo no significa saciedad de ser algo. Hace falta recordar que la conciencia debe conducirnos del plano del en-sí al plano del para-sí.

Nuestro vaciamiento no radica en una exclusiva y estrecha relación con el en-sí. Es posible direccionar la relación para-sí-para-sí en unas coordenadas de inclusión del otro, es decir, a partir de relaciones horizontales que confronten la nada con un nosotros nada, una nada compartida, nunca cosificada. Pero en Sartre esa nada equivale a soledad. Cuando el filósofo de la libertad 
asocia el ser para otros con el infierno está replegando la nada. Y la nada no es posible sino como nada comunicada. Se comunica la nada, no el ser. Claro está, en esa relación, el otro puede ser tomado como un infierno cuando se delega en él la responsabilidad de ser. En este caso, sí convendría una separación positiva, que sería respuesta personal, vaciamiento y búsqueda del ser. En consecuencia, las relaciones con el otro en esta reflexión sobre la ausencia pretenden una comunicación de un en-sí configurado intersubjetivamente. Buscamos lo que nos hace únicos, una historia particular que se extiende a la posibilidad de proyectar la nada para nunca perder esa ironía sartriana que define el hombre en un hacer, un hacer que también se desenmascara y se escinde.

\section{EL OBRAR ONTOLÓGICO}

En terminología sartriana, el para-sí es libertad ontológica pues obra, se hace-en-el-mundo y depende de sus elecciones, más aún, de las relaciones que establece con el en-sí y otros para-sí. Esas relaciones denotan una parte de su ser. Pero en este punto conviene acentuar la tensión, es decir, la ausencia, el ser sin máscara que aparece en todo momento, la conciencia de nada. Así la nada constituye ese algo del para-sí que Sartre concentró en el correlato. Su tensión de la nada y el ser se mantuvo en el extremo husserliano: ese algo estaba lleno. Ahora, en nuestra tensión hablamos también de un alguien vacío, de una nada, conciencia de nada. El ser del hombre no está-ahí, su ser-ahí es un ser en otra parte, un ser proyectado, un ser aplazado.

Si captamos la intencionalidad de la conciencia a partir de las relaciones posibles, comprendemos la nada en el ser, la nada que nos recupera y nos responsabiliza, la nada que sitúa al hombre entre un mundo construido, configurado y la significación de sus propias posibilidades. La conciencia siempre mira a lo lejos, y en ese mirar a lo lejos descubre lo que le falta, apuntando siempre, señalando su objetivo, dibujándolo en aquella historia que escriben sus acciones. En efecto, podemos preguntar: ¿qué lugar ocupa el obrar humano en esta reflexión sobre la ausencia? ¿Logra esta configuración resignificar la comprensión del hombre contemporáneo desde El ser y la nada?

A la primera pregunta que orienta este numeral, debemos anteponer un supuesto basado en la lectura de Heidegger. Recordemos que Heidegger retoma la pregunta por el sentido del ser, partiendo de la facticidad misma del Da-sein, de su $D a$, de «[...] ese existir en cada ocasión» (Heidegger, 2011, p. 25), sin una apropiación teorética inicial en la que se inscribe la intuición reflexiva de Husserl (Escudero, 2010). Este rasgo particular de la interpretación heideggeriana se alimenta del llamamiento clave de la fenomenología, iniciado por su maestro: a las cosas mismas. Pero su preocupación por el sentido del ser del ente le permite instaurar una posición radical, que va de la fenomenología reflexiva de Husserl a una fenomenología hermenéutica. Jesús Adrián Escudero esboza esa articulación temática y metodológica de su obra temprana, especialmente en la quinta parte de su texto Heidegger y la genealogía de la pregunta por el ser. También es preciso resaltar los trabajos de Ramón Rodríguez (1997) y Ángel Xolocotzi (2004) en torno a ese giro hermenéutico de la fenomenología. 
Existe una pre-comprensión del ser en un ente que pregunta por su ser, en el $D a$ del Dasein, en la temporalidad como su horizonte. Heidegger debe denunciar ese olvido del ser, un ser oscurecido en totalidades que daban cuenta de un contexto específico e igualmente de preocupaciones específicas: la preocupación por el Dios judeocristiano y la razón, como faro orientador de la ciencia en el proyecto moderno. A fin de cuentas, totalidades en las que se despliega la acción de equiparar el Ser de los entes con un Ente supremo: Dios, Mundo, Razón.

El ser era equiparado a una totalidad entitativa e incluso lógica -la «universalidad» del género ${ }^{2}$ - que envolvía el sentido de los demás entes en orden secundario. Nos referimos particularmente al ser aristotélico, que se comprende por analogía y que, por ende, se puede predicar de múltiples maneras: «la expresión «algo que es» se dice en muchos sentidos, según distinguimos ya con anterioridad en el tratado Acerca de cuántos sentidos (tienen ciertos términos). De una

2 En la primera parte Ser y Tiempo, Heidegger denuncia ese olvido del ser, que lo guiará al análisis existencial del Dasein: «Pero la «universalidad" del "ser" no es la del género. El "ser" no constituye la región suprema del ente en tanto que éste se articula conceptualmente según género y especie: oúte tò ón génos. La «universalidad" del ser "Sobrepasa» toda universalidad genérica. El "ser» es en la nomenclatura de la ontología medieval, un «trascendental» ("trascendens"). La unidad de este "universal» trascendental frente a la multiplicidad de los supremos conceptos genéricos quiditativos fue reconocida por Aristóteles como la unidad de la analogía. Con este descubrimiento, Aristóteles, pese a su dependencia respecto del cuestionamiento ontológico de Platón, puso el problema del ser sobre una base fundamentalmente nueva. Pero tampoco él logró disipar la oscuridad de estas conexiones categoriales. La ontología medieval discutió copiosamente el problema, especialmente en las escuelas tomista y escotista, sin llegar a claridad de fondo. Y cuando, finalmente, Hegel determina el "ser» como lo «inmediato indeterminado" haciendo de esta definición la base para todo el ulterior despliegue categorial de su Lógica, sigue mirando en la misma dirección que la ontología antigua, con la única diferencia que deja de mano el problema, ya planteado por Aristóteles, frente a la multiplicidad de las "categorías» quiditativas» (p. 24). parte, en efecto, significa el qué-es y algo determinado y, de otra parte, la cualidad, la cantidad o cualquier otra de las cosas que se predican de este modo» (Aristóteles, 1028a, 10). Este ser estaba enmarcado en todo un sistema de construcciones categoriales que operaban simultáneamente a partir de la silogística. Ese ser se predicaba, se hacía presente en la pregunta por el ser y en un conjunto de categorías.

Ahora bien, quitando esa analogía y entregando el ser a su sentido ontológico, a la facticidad misma en que ya se tiene una comprensión previa del ser, separándolo de los entes y entregándolo a su acontecer, encontramos una oportunidad: «el concepto de «ser» es, más bien, el más oscuro» (Heidegger, 2014, p. 13). Existe una particularidad en esta aproximación ontológica: la aletheia aristotélico-tomista de la presencia no da lugar a lo latente, al ser que se vela, porque es "presencia sin sombra», al acontecimiento en que el abismo del ser se abre al otro inicio en el ensamble de la resonancia, el pase, el salto, la fundación, los futuros y el último dios (Heidegger, 2006). Heidegger tendrá que enfrentar los tres prejuicios en que se enmarca el olvido del ser, a saber: como concepto «universal», como concepto «indefinible» y como concepto «evidente» por sí mismo (Heidegger, 2014, p. 24-25). Ese olvido del ser, no obstante, abre una posibilidad.

Volvamos al para-sí sartreano, distanciado de la analítica existencial de Heidegger en tanto radicaliza la ausencia de la libertad, que tematiza el en-sí. En esa ausencia hay primero una conciencia de algo: pervive la intencionalidad de Husserl como correlación de reflexividad. Por tanto, conciencia de ser y conciencia de nada ponen en juego esa doble 
conciencia: una aproximación no justifica la patencia absoluta del ser. Más aún, cuando acercamos esa aproximación a una conciencia de nada, es decir, de la ausencia que reconoce el hombre en su propia condición, descubrimos una postura de matiz nihilista en Sartre:

La realidad-humana es libre porque no es suficiente; porque está perpetuamente arrancada a sí misma, y lo que ella ha sido está separado por una nada de lo que es y de lo que será; y, por último, porque su mismo ser presente es nihilización en la forma de reflejo-reflejante. El hombre es libre porque no es sí-mismo, sino presencia a sí. El ser es lo que no puede ser libre. La libertad es precisamente la nada que es sida en el meollo del hombre y que obliga a la realidad-humana a hacerse en vez de ser. (Sartre, 2008, p. 615)

La postura de matiz nihilista de Sartre está arraigada en el devenir, en el tiempo, en la posibilidad, en los lanzamientos sucesivos de la nada, en un saltar al vacío, en un reconocer la miseria del que, siendo, se elige; es la realidad-humana. Por ello, en esa búsqueda del ser que nosotros desplazamos a una antropología de la posibilidad, el tiempo aparece como elemento capital: «el Para-sí, surgiendo en el ser como nihilización del En-sí, se constituye a la vez en todas las dimensiones posibles de nihilización» (Sartre, 2008 , p. 205). Esa temporalidad es capital en la filosofía de Heidegger.

La existencia nos revela la temporalidad, una temporalidad que ya tiene para sí misma el deseo y la exigencia de ser, la libre elección. De hecho, podemos interpretar la conciencia de necesidad, es decir, la libertad, como una exigencia de ser (Sartre, 2008). La libertad tiene que ser ontológica, ya que no depende de unas condiciones empíricas específicas, sino de su necesidad y de sus posibilidades. La libertad sería también una tensión que refleja la necesidad de negar aquello que no le es propio, ser algo, y desplegar sus posibilidades, su intencionar, su trasegar, su caminar con la mirada en el horizonte.

En el núcleo de la libertad estamos expuestos, nuestra temporalidad se patentiza a partir de la tematización del en-sí. Pero la temporalidad no es accesoria. En nuestro caso, la temporalidad tendría que ver con una elección de la finitud, de la búsqueda, del obrar en tensión, en ausencia. Aludimos a un obrar en ausencia que oscila entre el ser y la nada: el ser como objetivo y la nada como punto de partida. Ese ser es lo más oscuro, porque se patentiza en la conciencia de nada.

La conciencia de nada, la conciencia que arranca los sucedáneos de plenitud, prolonga una especie de agonía, un gerundio de la libertad que se nihiliza a sí misma haciendo posible la tensión. Por lo menos, una tensión que guarda una imagen borrosa a lo lejos, una teleología que se integra a la condición primera del ser-libre, del existir-libre para ser. Sartre es explícito al concluir El ser y la nada: «escoge, pues, no recuperarse sino huirse, no coincidir consigo mismo, sino estar siempre a distancia de sí» (Sartre, 2008, p. 842). Luego, ¿qué lugar ocupa el obrar?

La realidad humana es la tensión, el abismo que hay entre dos totalidades: la nada, una destotalizada, y el ser, la unificación proyectada. Si esa tensión hace posible la permanente oscilación del hombre que sube su piedra para perderla en la cima, entonces el 
obrar tampoco es un sucedáneo. En el obrar construimos lo que somos, nos hacemos la posibilidad de lo que somos. No obstante, en cada acción se patentiza la ausencia de aquella libertad que siempre se intenciona. El obrar es ontológico, porque nunca es suficiente. El obrar es ontológico en la medida en que pone de relieve la tensión original. Terminamos por devolvernos a nuestra conciencia de nada. Y así, la existencia no solo queda reducida a devenir, sino también a oscilación.

La existencia no es únicamente el devenir, la búsqueda, la posibilidad de una libertad que procura una identidad. La existencia parte de la relación fenomenológica con el en-sí. Tal vez en esta relación de tematización expresamos nuestro deseo de configurar una esencia que integra tanto el núcleo como lo vivido; en otras palabras, una esencia precedida por un ser fundamental, una conciencia de nada y todos los esfuerzos de invención y desvelamiento de nosotros mismos. Una esencia a partir de la tensión, de lo oscuro de ese ser, de la ausencia que nos hace demasiado humanos.

\section{Para concluir}

En esta reflexión que enmarcó la categoría ausencia como lugar de la tensión que se libra entre la nada humana y el ser en tanto plenitud, la libertad significa también elección de la finitud: «el acto mismo de libertad es, pues, asunción y creación de la finitud. Si me hago, me hago finito $\mathrm{y}$, por eso mismo, mi vida es única» (Sartre, 2008, p. 738). De hecho, entendemos por finitud la libre elección de ser todo lo que hacemos para no caer en una anomia devastadora de las posibilidades que vemos pasar en múltiples historias del mundo en que vivimos. No podemos desconocer que un mundo interconectado y plagado de información, de felicidades sucesivas que se venden y se tiran, disuelve esta estructura (Lipovetsky 2011).

El hombre no podría reconocerse a sí mismo más que dentro de la gran maquinaria que lo absorbe en su soledad y en sus posibilidades. Un mundo que todo lo inmediatiza, que nos entrega un sentido de realidad ligado a discursos de poder sobre el otro, es un mundo sin nosotros. Nos hemos identificado con nuestro mundo en demasía. Y esa identificación es la que nos hace olvidar de nosotros mismos, de nuestra exigencia ontológica. No hemos hecho más que ponerle máscaras a nuestra ausencia. Por eso nuestro mundo, ese mundo plagado de información infinita, es un mundo que nos enseña a jugar y a olvidar: jugamos a no estar; nos entretiene la posibilidad de olvidar lo que realmente deseamos.

La ausencia sitúa al hombre en el límite. No es que lo separe de la cultura, de las costumbres y de las prácticas sucesivas que podrían absorberlo en identificaciones y costumbres homogeneizantes. Situar al hombre en el límite significa emplazarlo en el punto medio donde comienza a individuarse, pero también donde comienza a ser parte de una construcción común del mundo. En esta medida, se abre una posibilidad: la tensión entre ese ser que proyectamos y esa nada que nihiliza el en-sí, incluso las acciones que tienden a sustituir la búsqueda por una cansada conclusión que podríamos llamar esencia del acomodo o elección de la quietud, está ligada a otra tensión: la tensión de hacerse uno y no perderse cuando se es parte de un 
grupo y de una identidad socio-cultural. El hombre no puede eludir esa condición.

La ausencia es tensión de individuación proyectiva y una asignación de nombre propio a una esencia construida. También constituye una tensión de buscar estar dentro, estando fuera, perder la familiaridad con un mundo humano que construye discursos capaces de hacer perder la posibilidad. Encontramos una primera condición: la libertad. Pero no una libertad como valor, sino como condición fundamental del para-sí:

La libertad es total e infinita, lo que no significa que no tenga límites, sino que no los encuentra jamás. Los únicos límites con que la libertad choca a cada instante son los que ella se impone a sí misma y de los cuales hemos hablado, a propósito del pasado, los entornos y las técnicas. (Sartre, 2008, p. 718)

En la concepción de una libertad ontológica, la ausencia se atiene a ella como núcleo donde se ejecuta ese vaciamiento constante de conocimientos que dan sentido al mundo. Un conocimiento que simultáneamente nos descubre nuestra conciencia de nada. Y la conciencia de nada, una conciencia ontológica, nos revela en el centro de El ser y la nada un permanente aplazamiento del ser que buscamos, un re-conocimiento personal de precariedad y, por tanto, una tensión que no está totalmente del lado del ser, pero tampoco del lado de la nada. La libertad siempre está en medio. No solo apuntala al ser; siempre está mirándose como nada: «Lo que tratamos de definir es el ser del hombre en tanto que condiciona la aparición de la nada, y ese ser nos ha aparecido como libertad. Así, la libertad, como condición requerida para la nihilización de la nada, no es una propiedad que pertenezca entre otras a la esencia del ser humano» (Sartre, 2008, p. 68). Al preguntar por el ser, patentizamos la nada, reconocemos la nada que somos. Entonces la esencia forma parte de esas elecciones, de esas acciones, y como en ellas no termina por agotarse, queda en manos de un sentido de posibilidad.

No es gratuito que El ser y la nada aparezca en la época de los genocidios, los campos de concentración y el derrumbe de los ideales humanos, construidos durante la modernidad de un animal racional que abría camino hacia la luz con su ser. También podemos destruir el en-sí de la cultura y perder el rumbo. Cuando somos expulsados de ese paraíso prometido del proyecto moderno, convertido en un panorama desolador, no queda más que vagar, elegir el destierro y la posibilidad. Frente a una realidad como esa, queda el sentido de posibilidad, una ontología del hombre que se busca a sí mismo.

\section{REFERENCIAS}

Aristóteles. (1994). Metafísica. Trad. Tomás Calvo Martínez. Madrid: Gredos.

Cruz Vélez, D. (2001). Filosofía sin supuestos: de Husserl a Heidegger. Manizales: Universidad de Caldas.

De Beauvoir, S. (2006). La plenitud de la vida. Buenos Aires: Sudamericana.

Escudero, J. A. (2010). Heidegger y la genealogía de la pregunta por el ser. Una articulación temática y metodológica de su obra temprana. Barcelona: Herder.

Gerassi, J. (1993). Jean-Paul Sartre: La conciencia odiada de su siglo. Trad. María Victoria Mejía Duque. Bogotá: Norma. 
Givone, S. (2001). Historia de la nada. Trad. Alejo González y Demian Orosz. Buenos Aires: Adriana Hidalgo.

Heidegger, M. (2006). Aportes a la filosofía. Acerca del evento. Trad. Dina V. Picotti C. Buenos Aires: Biblos. . (2014). Ser y tiempo. Trad. Jorge Eduardo Rivera C. Madrid: Trotta. . (2011). Ontología. Hermenéutica de la facticidad. Trad. Jaime Aspiunza. Madrid: Alianza.

Hobsbawm, E. (2010). Historia del siglo XX. Trad. Juan Faci, Jordi Ainaudy y Carmen Castells. Buenos Aires: Crítica.

Husserl, E. (1997). Ideas relativas a una Fenomenología Pura y una Filosofía Fenomenológica. México: Fondo de Cultura Económica.

Lipovetsky, G. (2011). La felicidad paradójica: Ensayo sobre la sociedad del hiperconsumo. 2 ed. Trad. Antonio-Prometeo Moya. Barcelona: Anagrama.

López Sáenz, M.-C. (2003). “Apuntes antropológicos basados en una relación: Maurice Merleau-Ponty y Jean-Paul Sartre", en Juan Fernando Sellés, ed., Modelos antropológicos del siglo XX. Pamplona: Cuadernos de anuario filosófico: pp. 83-114.
Murdoch, I. (2007). Sartre: Un racionalista romántico. Trad. Ernesto Bottini Rodríguez y Nicole Laffay Ricard. Barcelona: Debolsillo.

Rodríguez, R. (1997). La transformación hermenéutica de la fenomenología. Madrid: Tecnos.

Roubiczek, P. (1968). El existencialismo. Barcelona: Nueva Colección Labor.

Safranski, R. (2005). El mal o el drama de la libertad. Trad. Raúl Gabás. Barcelona: TusQuets.

Sartre, J-P. (1968). El hombre y las cosas. 3 ed. Trad. Luis Echávarri. Buenos Aires: Losada.

. (1985). El existencialismo es un humanismo. Buenos Aires: Ediciones del 80. . (1996). Verdad y Existencia. Trad. Alicia Puleo. Barcelona: Paidós. . (2008). El ser y la nada: Ensayo de ontología fenomenológica. Trad. Juan Valmar. Buenos Aires: Losada.

Uribe Merino, C. (2005). Por los caminos de Sartre. Medellín: Hombre Nuevo.

Xolocotzi, A. (2004). Fenomenología de la vida fáctica: Heidegger y su camino a «Ser $y$ tiempo». México: Plaza y Valdés. 